\title{
Note
}

\section{Effect of Germination on the Antioxidant Capacity of Pigmented Rice (Oryza sativa L. cv. Superjami and Superhongmi)}

\author{
Soo Im $\mathrm{CHUNG}^{*}$, Lara Marie Pangan Lo and Mi Young KAnG \\ Department of Food Science and Nutrition, Brain Korea 21 Plus, Kyungpook National University, 1370 Sankyuk-dong, \\ Daegu, 702-701, Republic of Korea
}

Received October 22, 2015 ; Accepted January 4, 2016

The effect of germination on the antioxidant capacity of pigmented and non-pigmented rice was investigated. The blackish purple Superjami, reddish-brown Superhongmi, and ordinary non-pigmented brown rice were germinated for $72 \mathrm{~h}$. The germinated rice grains were extracted with $80 \%$ methanol and their antioxidant activities and compounds were analyzed. Germination substantially increased the free radical scavenging activity, reducing power, ferrous chelating ability, and superoxide dismutase activity in all the rice samples. The anthocyanin, tannin, phenolic, phytic acid, tocopherol, and tocotrienol contents were markedly higher in germinated rice compared to those of the non-germinated ones. The pigmented varieties exhibited greater antioxidant capacity and higher amounts of antioxidant compounds than the non-pigmented brown rice in both germinated and non-germinated forms. Superjami showed higher antioxidant activities and anthocyanin, phenolic, tocopherol, and tocotrienol contents than Superhongmi. These findings illustrate that germination could increase the antioxidant compounds and enhance the antioxidant capacity of pigmented rice which may be useful as functional foods.

Keywords: pigmented rice, germination, antioxidant activity, antioxidant compounds

\section{Introduction}

Germination has been shown to improve the nutritional value and increase the amount of bioactive compounds in various cereal grains including rice, oat, wheat, and barley (Hubner and Arendt, 2013). It has also been reported that germination could improve the texture and eating quality of brown rice (Wu et al., 2013b). This process involves soaking of the grains in water for a few days to induce slight germination. The rice is considered germinated when the primary root is already visible (Moongngarm and Khomphiphatkul, 2011). A number of studies have shown that germinated rice possesses various pharmacological properties, such antidiabetic, antihyperlipidemia, antioxidant, and anticancer (Mohd Esa et al., 2013; Patil and Khan, 2011; Wu et al., 2013b). Biochemical changes occur during germination of rice which causes softening of the endosperm and an increase in nutrient bioavailability (Islam and Becerra, 2012; Patil and Khan, 2011).

Pigmented rice varieties are rice grains with colored pericarp and have been shown to have higher amounts of nutrients and greater antioxidant capacity than ordinary non-pigmented rice (Laokdiluk et al., 2011; Kang et al., 2013). A study conducted by Nam et al. (2005) revealed that extracts from pigmented rice brans have anticancer and antimutagenic properties. Moreover, consumption of pigmented rice has been associated with reduced risk of developing hyperlipidemia and cardiovascular disease (Ling et al., 2001). Due to the high antioxidant potential and functional properties of pigmented rice, new lines of this variety with enhanced biofunctional properties are continuously being developed and produced. In Korea, new pigmented rice varieties, Superjami and Superhongmi, have been recently developed through conventional breeding. Superjami, a blackish purple rice, 
contains high amounts of cyanidin-3-glucoside, an anthocyanin that has strong antioxidant capacity (Kwon et al., 2011). Superhongmi, a reddish brown rice, contains acetylated procyanidins that have free radical scavenging activity (Seo et al., 2011).

With the growing health problems and rapidly increasing incidences of metabolic diseases worldwide, natural foods with strong health-promoting properties are greatly needed. While a number of studies have been conducted on the antioxidant capacity of pigmented rice and physiological functions of germinated brown rice (Kang et al., 2013; Lin et al., 2015; Mohd Esa et al., 2013; Shen et al., 2009; Wu et al., 2013b), there were limited reports on the functional properties of germinated pigmented rice (Jiapong et al., 2011; Sutharut and Sudarat, 2012; Umnajkitikorn et al., 2013). The present study was carried out to determine the effect of germination on the antioxidant activity of pigmented rice Superjami and Superhongmi, in comparison to that of the ordinary non-pigmented brown rice. The antioxidant components, such as anthocyanin, tannin, phenolic compounds, phytic acid, tocopherol, and tocotrienol, of the germinated and non-germinated rice samples were also analyzed.

\section{Materials and Methods}

Rice samples and chemicals Whole grain pigmented rice, Superjami and Superhongmi, and ordinary non-pigmented brown rice Hwacheong were obtained from the Department of Agricultural Science, Korea National Open University. They were grown from May to October 2014 under the required cultivation conditions. All chemicals used in this study are of analytical grade and purchased from Sigma-Aldrich Chemical Co. (St. Louis, MO, USA).

Germination of rice samples The rice grains were germinated following the methods described by Wu et al. (2013a) with slight modifications. Briefly, 2 sets of $60 \mathrm{~g}$ grains from each rice sample were washed twice with distilled water and $70 \%$ ethanol. The first set was placed evenly in a tray laid with paper towel and dried in an oven at $50^{\circ} \mathrm{C}$ for $2 \mathrm{~h}$ to lower the moisture content. The dried rice grains, which served as the control or non-germinated samples, were ground and pulverized using a grinding machine (HMF3250S, Hanil Electronics, Seoul, South Korea), packed in hermetically sealed Ziploc plastic bags, and stored at $-20^{\circ} \mathrm{C}$ until further analysis. The second set of rice grains was placed evenly in a tray overlaid with cotton pads and cheesecloth and enough water was added until the grains were soaked. The whole tray was covered with a clean transparent plastic wrap with holes to accommodate proper moisture condition and incubated at $30^{\circ} \mathrm{C}$. The rice grains were checked every $24 \mathrm{~h}$ to ensure there was no foul odor and fungal growth. After $72 \mathrm{~h}$, the germinated rice grains were dried, pulverized, and stored using the same method described above for the non-germinated grains. The 72-h germination period was selected as the optimum time for rice germination based on the results of our preliminary investigation. Our initial observation revealed that the antioxidant activity and the amount of antioxidant components increased with germination time (data not shown), however, fungi developed in the germinated rice after $72 \mathrm{~h}$.

Preparation of methanolic extracts from germinated and nongerminated rice Methanolic extracts from the rice samples were prepared using the method of Dutta et al. (2012). Briefly, the rice powder $(3 \mathrm{~g})$ was mixed with $80 \%$ methanol $(30 \mathrm{~mL})$ and the mixture was subjected to overnight shaking at $25^{\circ} \mathrm{C}$ using a twister machine (VS-96TW, Vision Scientific Co., Ltd., Daejeon, South Korea), followed by centrifugation at $10,000 \mathrm{rpm}$ for $10 \mathrm{~min}$. The extracts were then filtered using a $0.45 \mu \mathrm{M}$ pore size syringe driven filter (Chromdisc, E.Chrom Science Inc., Daegu, South Korea) and stored at $-20^{\circ} \mathrm{C}$ until further analysis.

Determination of antioxidant activities of the methanolic extracts

1,1-diphenyl-2-picrylhydrazyl (DPPH)-radical scavenging activity The DPPH-radical scavenging activity of the methanolic extracts was measured using the method of Chakuton et al. (2012). Briefly, four different concentrations of the methanolic extract ( 0.5 , 1,5 , and $10 \mathrm{mg} / \mathrm{mL}$ ) were prepared and an aliquot of $200 \mu \mathrm{L}$ each was added to $1.8 \mathrm{~mL}$ of DPPH solution in absolute ethanol. The mixture was left at room temperature in the dark for $1 \mathrm{~h}$. The absorbance at $515 \mathrm{~nm}$ was measured and the scavenging activity was calculated using the following equation:

DPPH radical scavenging activity $(\%)=\left[1-\left(\mathrm{A}_{\text {sample }}\right) / \mathrm{A}_{\text {blank }}\right] \times 100 \cdots \cdots$ Eq. 1

The effective concentration at which $50 \%\left(\mathrm{EC}_{50}\right)$ of the DPPH radicals are scavenged was calculated by interpolation from linear regression analysis. Butylated hydroxyanisole (BHA) was used as standard.

2,2'-azinobis-(3-ethylbenzthiazoline-6-sulfonic acid) [ABTS] radical scavenging activity The ABTS radical scavenging activity was determined according to the method of Privita-Edwina et al. (2014) with slight modifications. The ABTS was dissolved in distilled water $(7.4 \mathrm{mM})$ and mixed with potassium persulfate solution $(2.6 \mathrm{mM})$ in equal amounts. The solution was allowed to stand at ambient temperature in the dark for 16-24 h. Absorbance of the resulting solution was between 1.4 to 1.5 readings at $734 \mathrm{~nm}$ prior to use. The methanolic extract $(500 \mu \mathrm{L})$ was added to $1.0 \mathrm{~mL}$ of ABTS solution and the mixture was allowed to stand for $30 \mathrm{~min}$. The absorbance was measured at $734 \mathrm{~nm}$. Ascorbic acid was used as standard and the results were expressed as mg of ascorbic acid equivalent (AAeq) per $100 \mathrm{~g}$ of extract.

Hydroxyl radical scavenging activity The hydroxyl radical scavenging activity of the methanolic extracts was determined according to the method of Privita-Edwina et al. (2014). Briefly, $200 \mu \mathrm{L}$ of $10 \mathrm{mM} \mathrm{H}_{2} \mathrm{O}_{2}$ was added to the reaction mixture consisting of $200 \mu \mathrm{L}$ of $10 \mathrm{mM} \mathrm{FeSO}_{4} /$ EDTA solution, $200 \mu \mathrm{L}$ of $10 \mathrm{mM}$ 2-deoxyribose, $1 \mathrm{~mL}$ of $0.1 \mathrm{M}$ sodium phosphate buffer $(\mathrm{pH}$ 7.4) and $200 \mu \mathrm{L}$ of the methanolic extracts $(0.5,1,5$, and $10 \mathrm{mg} /$ 
$\mathrm{mL}$ ). The mixture was incubated at $40^{\circ} \mathrm{C}$ for $2 \mathrm{~h}$ and added with $1 \mathrm{~mL}$ of $2.8 \%$ trichloroacetic acid (TCA) and $1 \mathrm{~mL}$ of $0.67 \%$ thiobarbituric acid. The mixture was heated to $100^{\circ} \mathrm{C}$ for $10 \mathrm{~min}$. The absorbance was measured at $532 \mathrm{~nm}$ and the scavenging activity was calculated as follows:

Scavenging activity $(\%)=\left[1-\left(\mathrm{A}_{\text {sample }}\right) / \mathrm{A}_{\text {blank }}\right] \times 100 \quad \cdots \cdot$ Eq. 2

The $\mathrm{EC}_{50}$ of the scavenging activity was calculated using linear regression analysis and ascorbic acid was used as standard for comparison.

Iron $\left(\mathrm{Fe}^{2+}\right)$ chelating ability The ability of the methanolic extracts to chelate metals was determined using the method of Sudan et al. (2014). Four different concentrations of the extracts $(0.5,1,5$, and $10 \mathrm{mg} / \mathrm{mL})$ were prepared and an aliquot of $100 \mu \mathrm{L}$ was added to $50 \mu \mathrm{L}$ of $2 \mathrm{mM} \mathrm{FeCl}_{2}$. Subsequently, $100 \mu \mathrm{L}$ ferrozine and $1.7 \mathrm{~mL}$ of $95 \%$ ethanol were added and the mixture was left to stand at room temperature for $10 \mathrm{~min}$. The absorbance of the resulting solution was measured at $562 \mathrm{~nm}$ and the iron chelating ability was calculated using the following equation:

Chelating ability $(\%)=\left[1-\left(\mathrm{A}_{\text {sample }}\right) / \mathrm{A}_{\text {blank }}\right] \times 100 \quad \cdots \cdot$ Eq. 3

EDTA was used as standard and the $\mathrm{EC}_{50}$ value was calculated using linear regression analysis.

Reducing power The reducing power of the methanolic extracts was determined using the method of Mau et al. (2003) with some modifications. The extract $(500 \mu \mathrm{L})$ was mixed with $800 \mu \mathrm{L}$ of $0.2 \mathrm{M}$ phosphate buffer (pH 6.6) and $500 \mu \mathrm{L}$ of $5 \mathrm{mM}$ $\mathrm{K}_{2} \mathrm{FeCN}_{6}$. The mixture was incubated in water bath at $50^{\circ} \mathrm{C}$ for $20 \mathrm{~min}$ to reduce the ferricyanide to ferrocyanide. It was added with $10 \%$ TCA $(500 \mu \mathrm{L})$ and centrifuged at $5000 \mathrm{rpm}$ for $10 \mathrm{~min}$. The supernatant was added with $500 \mu \mathrm{L}$ of distilled water and $100 \mu \mathrm{L}$ of $\mathrm{FeCl}_{3}$. The mixture was shaken vigorously and the absorbance was measured at $700 \mathrm{~nm}$. A higher absorbance indicates a higher reducing power. The $\mathrm{EC}_{50}$, effective concentration at which the absorbance was 0.5 , was obtained by linear regression analysis. Ascorbic acid was used as standard.

Superoxide dismutase (SOD)-like activity To assess the capability of the methanolic extracts to scavenge superoxide anions, superoxide dismutase assay was performed following the method of Marklund and Marklund (1974) with some modifications. The reaction mixture, consisting of $1 \mathrm{~mL}$ of $50 \mathrm{mM}$ Tris-HCl/10 mM EDTA buffer ( $\mathrm{pH} 8.5$ ), $60 \mu \mathrm{L}$ of $7.2 \mathrm{mM}$ pyrogallol, and $60 \mu \mathrm{L}$ of the methanolic extract, was incubated at $25^{\circ} \mathrm{C}$ for $10 \mathrm{~min}$. The mixture was added with $30 \mu \mathrm{L}$ of $1 \mathrm{~N} \mathrm{HCl}$ and the absorbance was measured at $420 \mathrm{~nm}$. The SOD-like activity was calculated using the following equation:

SOD-like activity $(\%)=\left[1-\left(\mathrm{S}_{\mathrm{abs}}-\mathrm{B}_{\mathrm{abs}}\right) / \mathrm{C}_{\mathrm{abs}}\right] \times 100 \cdots \cdots$ Eq. 4

where $\mathrm{S}_{\mathrm{abs}}$ was the absorbance of the sample solution, $\mathrm{B}_{\mathrm{abs}}$ was the absorbance of the reaction mixture containing buffer instead of pyrogallol, and $\mathrm{C}_{\mathrm{abs}}$ was the absorbance of the reaction mixture containing buffer instead of the methanolic extract.

Determination of total anthocyanin content The total anthocyanin content of the methanolic extract was determined using pH-differential method (Chakuton et al. 2012). Briefly, the extract was diluted in $0.025 \mathrm{M} \mathrm{KCl}$ buffer $(\mathrm{pH} 1.0)$ and placed in the dark at room temperature for $30 \mathrm{~min}$. The absorbance was measured at $520 \mathrm{~nm}$ and $700 \mathrm{~nm}$. The methanolic extract was mixed with $0.4 \mathrm{M}$ sodium acetate buffer $(\mathrm{pH} 4.5)$ and the absorbance was measured again at $520 \mathrm{~nm}$ and $700 \mathrm{~nm}$. The results were calculated using malvidin-3-O-glucoside equation:

Total anthocyanin content $(\mathrm{mg}$ malvidin $/ 100 \mathrm{~g}$ rice $)=$ $(\mathrm{A} \times \mathrm{MW} \times \mathrm{DF} \times 1000) /(\varepsilon \times 1) \quad \cdots \cdots$ Eq. 5

where $\mathrm{A}$ (absorbance) $=\left(\mathrm{A}_{520 \mathrm{~nm}}-\mathrm{A}_{700 \mathrm{~nm}}\right) \mathrm{pH} 1.0-\left(\mathrm{A}_{520 \mathrm{~nm}}-\mathrm{A}_{700 \mathrm{~nm}}\right)$ $\mathrm{pH} 4.5, \mathrm{MW}=$ molecular weight of malvidin-3-O-glucoside (493.5 g/mol, $), \mathrm{DF}=$ dilution factor for sample $(0.4 \mathrm{~mL})$, and $\varepsilon=$ molar extinction coefficient $(28,000)$.

Determination of tannin content Colorimetric estimation of the tannin content based on the blue color formed by the reduction of phosphotungstomolybdic acid by tannin-like compounds in alkaline medium was determined following the method described by Padma et al. (2013). The methanolic extract $(200 \mu \mathrm{L})$ was mixed with $1.5 \mathrm{~mL}$ distilled water, then Folin-Denis reagent $(100 \mu \mathrm{L})$ and $\mathrm{Na}_{2} \mathrm{CO}_{3}(200 \mu \mathrm{L})$ were added. The absorbance of the resulting solution was measured at $700 \mathrm{~nm}$. The total tannic acid content was expressed as $\mathrm{mg}$ of tannic acid equivalent (TAE)/g of extract.

Determination of total phenolic content The total phenolic content of the methanolic extracts was measured using the FolinCiocalteu colorimetric method (Velioglu et al., 1998). The extract $(100 \mu \mathrm{L})$ was mixed with $2 \mathrm{~mL}$ of $2 \% \mathrm{Na}_{2} \mathrm{CO}_{3}$. After $3 \mathrm{~min}$, the mixture was then added with 50\% Folin-Ciocalteu's reagent $(100 \mu \mathrm{L})$. The absorbance was measured at $750 \mathrm{~nm}$ and the results were expressed as $\mathrm{mg}$ of gallic acid equivalents (GAE)/100 $\mathrm{g}$ of extract.

Determination of phytic acid content The phytic acid contents of the germinated and non-germinated grains were determined spectrophotometrically based on the method of Chakuton et al. (2012) with some modifications. Briefly, the rice powder (1.5 g) was extracted with $0.1 \mathrm{M} \mathrm{HCl}(10 \mathrm{~mL})$ by continuous shaking at $200 \mathrm{rpm}$ for $24 \mathrm{~h}$. The mixture was centrifuged at $3000 \mathrm{rpm}$ for $20 \mathrm{~min}$. The supernatant $(500 \mu \mathrm{L})$ was mixed with $1 \% \mathrm{FeCl}_{3}$ solution, heated at $100^{\circ} \mathrm{C}$ in a water bath, and then allowed to cool at ambient temperature until precipitate developed. The mixture was centrifuged at $5000 \mathrm{rpm}$ for $10 \mathrm{~min}$ and the supernatant $(100 \mu \mathrm{L})$ was mixed with 2,2' bipyridine solution. The solution was transferred to a 96-well culture plate and incubated for $5 \mathrm{~min}$. The absorbance was measured at $519 \mathrm{~nm}$. The method was calibrated with standard phytic acid solutions and the results were expressed as $\mathrm{mg}$ phytic acid equivalent/100 $\mathrm{g}$ of rice.

Determination of tocopherol and tocorienol contents The 
Table 1. Free radical scavenging activities of methanolic extracts from germinated and non-germinated pigmented rice.

\begin{tabular}{cccc}
\hline Antioxidant activity & Rice sample & Non-germinated & Germinated \\
\hline & Brown rice & $26.15 \pm 1.74^{\mathrm{a}}$ & $63.42 \pm 3.52^{\mathrm{a}^{*}}$ \\
DPPH radical scavenging activity (\%) & Superjami & $59.84 \pm 0.57^{\mathrm{c}}$ & $84.30 \pm 0.74^{\mathrm{c}^{*}}$ \\
& Superhongmi & $31.58 \pm 1.57^{\mathrm{b}}$ & $67.04 \pm 2.21^{\mathrm{b}^{*}}$ \\
& BHA & $92.61 \pm 1.47^{\mathrm{d}}$ & $92.61 \pm 1.47^{\mathrm{d}}$ \\
\hline ABTS radical scavenging activity (mg AAeq/100 g extract) & Brown rice & $15.83 \pm 1.95^{\mathrm{a}}$ & $65.96 \pm 1.57^{\mathrm{a}^{*}}$ \\
& Superjami & $108.75 \pm 1.80^{\mathrm{c}}$ & $143.63 \pm 2.38^{\mathrm{c}^{*}}$ \\
& Superhongmi & $58.92 \pm 1.35^{\mathrm{b}}$ & $118.13 \pm 3.36^{\mathrm{b}^{*}}$ \\
\hline & Brown rice & $44.05 \pm 0.54^{\mathrm{a}}$ & $56.54 \pm 0.71^{\mathrm{a}^{*}}$ \\
& Superjami & $48.57 \pm 0.71^{\mathrm{b}}$ & $65.75 \pm 0.71^{\mathrm{c}^{*}}$ \\
& Superhongmi & $47.86 \pm 0.68^{\mathrm{b}}$ & $62.27 \pm 0.57^{\mathrm{b}^{*}}$ \\
& Ascorbic acid & $87.57 \pm 1.25^{\mathrm{c}}$ & $87.57 \pm 1.25^{\mathrm{d}}$ \\
\hline
\end{tabular}

Values are means $\pm \mathrm{SD}(n=3)$. Means in the same column with different letters are significantly different at $P<0.05$. * indicates significant difference $(P<0.05)$ between germinated and non-germinated samples.

Table 2. Iron $\left(\mathrm{Fe}^{2+}\right)$ chelating ability, reducing power, and SOD-like activity of methanolic extracts from germinated and non-germinated pigmented rice.

\begin{tabular}{cccc}
\hline Antioxidant activity & Rice sample & Non-germinated & Germinated \\
\hline & Brown rice & $66.78 \pm 1.71^{\mathrm{a}}$ & $81.00 \pm 1.08^{\mathrm{a}^{*}}$ \\
$\mathrm{Fe}^{2+}$ chelating ability (\%) & Superjami & $83.97 \pm 0.43^{\mathrm{c}}$ & $88.82 \pm 0.53^{\mathrm{c}^{*}}$ \\
& Superhongmi & $79.37 \pm 0.42^{\mathrm{b}}$ & $86.73 \pm 0.52^{\mathrm{b}^{*}}$ \\
& EDTA & $95.44 \pm 0.09^{\mathrm{d}}$ & $95.44 \pm 0.09^{\mathrm{d}}$ \\
\hline & Brown rice & $0.25 \pm 0.00^{\mathrm{a}}$ & $0.48 \pm 0.01^{\mathrm{a}^{*}}$ \\
& Superjami & $0.50 \pm 0.01^{\mathrm{c}}$ & $0.82 \pm 0.01^{\mathrm{c}^{*}}$ \\
& Superhongmi & $0.35 \pm 0.01^{\mathrm{b}}$ & $0.59 \pm 0.01^{\mathrm{b}^{*}}$ \\
& Ascorbic acid & $0.83 \pm 0.01^{\mathrm{d}}$ & $0.83 \pm 0.01^{\mathrm{d}}$ \\
\hline & Brown rice & $5.10 \pm 0.95^{\mathrm{a}}$ & $40.71 \pm 2.57^{\mathrm{a}^{*}}$ \\
& Superjami & $10.35 \pm 0.80^{\mathrm{c}}$ & $77.90 \pm 2.58^{\mathrm{c}^{*}}$ \\
& Superhongmi & $7.65 \pm 0.55^{\mathrm{b}}$ & $46.27 \pm 0.36^{\mathrm{b}^{*}}$ \\
\hline
\end{tabular}

Values are means $\pm \mathrm{SD}(n=3)$. Means in the same column with different letters are significantly different at $P<0.05$. * indicates significant difference $(P<0.05)$ between germinated and non-germinated samples.

tocopherol $(\alpha, \beta$, and $\gamma)$ and tocotrienol $(\alpha, \beta$, and $\delta)$ contents of the methanolic extracts were determined according to the method described by Jeng et al. (2011). The extract was filtered through a $0.45 \mu \mathrm{M}$ filter membrane and analyzed using HPLC system equipped with fluorescence detector ( $\lambda \operatorname{ex} 298 \mathrm{~nm}, \lambda \mathrm{em} 328 \mathrm{~nm}$ ) and C18 analytical column $(4.6 \times 150 \mathrm{~mm}, 5 \mu \mathrm{m})$. The mobile phase was acetonitrile and methanol (60:40) with $1 \mathrm{~mL} / \mathrm{min}$ flow rate. The data were calibrated using standard tocopherol and tocotrienol set kits.

Statistical analysis Data were analyzed using one-way ANOVA (Statistical Package for Social Sciences software program version 22.0, SPSS Inc., Chicago, IL, USA) and the values were reported as mean \pm standard deviation (SD). The difference between the means was assessed using Tukey's test and independent student t-test. Statistical significance was considered at $p<0.05$.

\section{Results}

Free radical scavenging activities Germination significantly increased the DPPH, ABTS, and hydroxyl radicals scavenging activities of all the rice samples (Table 1). In both non-germinated and germinated conditions, Superjami exhibited the highest DPPH and ABTS scavenging activities, followed by Superhongmi, then the ordinary non-pigmented brown rice Hwacheong. The hydroxyl radical scavenging activity was also significantly higher in both pigmented rice methanolic extracts than that of the brown rice methanolic extract.

Ferrous ion chelating ability, reducing power, and SOD-like activity The pigmented rice samples showed significantly higher $\mathrm{Fe}^{2+}$ chelating ability, reducing power, and SOD-like activity than the non-pigmented rice (Table 2). The antioxidant activities markedly increased after germination for $72 \mathrm{~h}$ in all rice samples. The Superjami exhibited the highest $\mathrm{Fe}^{2+}$ chelating ability, reducing power, and SOD-like activity in both germinated and non- 
Table 3. $\mathrm{EC}_{50}$ values of germinated and non-germinated pigmented rice methanolic extracts on DPPH and hydroxyl radicals scavenging assays, ferrous ion chelating activity, and reducing power.

\begin{tabular}{cccr}
\hline Antioxidant assay & Rice sample & Non-germinated & \multicolumn{1}{c}{ Germinated } \\
\hline & Brown rice & $20.58 \pm 1.52^{\mathrm{c}}$ & $14.27 \pm 0.47^{\mathrm{d}^{*}}$ \\
& Superjami & $7.07 \pm 0.36^{\mathrm{b}}$ & $3.81 \pm 0.15^{\mathrm{b}^{*}}$ \\
& Superhongmi & $17.93 \pm 1.59^{\mathrm{c}}$ & $6.80 \pm 0.61^{\mathrm{c}^{*}}$ \\
& BHA & $0.27 \pm 0.08^{\mathrm{a}}$ & $0.27 \pm 0.08^{\mathrm{a}}$ \\
\hline & Brown rice & $13.65 \pm 0.61^{\mathrm{c}}$ & $7.65 \pm 0.24^{\mathrm{c}^{*}}$ \\
& Superjami & $9.35 \pm 0.16^{\mathrm{b}}$ & $5.19 \pm 0.08^{\mathrm{b}^{*}}$ \\
& Superhongmi & $9.98 \pm 0.17^{\mathrm{b}}$ & $5.37 \pm 0.06^{\mathrm{b}^{*}}$ \\
& Ascorbic acid & $2.35 \pm 0.04^{\mathrm{a}}$ & $2.35 \pm 0.04^{\mathrm{a}}$ \\
\hline Fydroxyl radical scavenging $(\mathrm{mg} / \mathrm{mL})$ & Brown rice & $4.72 \pm 0.03^{\mathrm{d}}$ & $3.47 \pm 0.06^{\mathrm{c}^{*}}$ \\
& Superjami & $3.79 \pm 0.15^{\mathrm{b}}$ & $3.12 \pm 0.06^{\mathrm{b}^{*}}$ \\
& Superhongmi & $4.19 \pm 0.04^{\mathrm{c}}$ & $3.19 \pm 0.05^{\mathrm{b}^{*}}$ \\
& EDTA & $0.49 \pm 0.01^{\mathrm{a}}$ & $0.49 \pm 0.01^{\mathrm{a}}$ \\
\hline & Brown rice & $26.26 \pm 1.00^{\mathrm{d}}$ & $11.64 \pm 0.19^{\mathrm{d}^{*}}$ \\
& Superjami & $6.07 \pm 1.21^{\mathrm{b}}$ & $1.76 \pm 0.55^{\mathrm{b}^{*}}$ \\
& Superhongmi & $11.15 \pm 1.96^{\mathrm{c}}$ & $4.69 \pm 0.41^{\mathrm{c}^{*}}$ \\
& Ascorbic acid & $1.27 \pm 0.08^{\mathrm{a}}$ & $1.27 \pm 0.08^{\mathrm{a}}$ \\
\hline
\end{tabular}

Values are means $\pm \mathrm{SD}(n=3)$. Means in the same column with different letters are significantly different at $P<0.05$. * indicates significant difference $(P<0.05)$ between germinated and non-germinated samples.

germinated forms.

$E C_{50}$ values on antioxidant assays $\mathrm{The}_{50}$ values on $\mathrm{DPPH}$ scavenging activity, $\mathrm{Fe}^{2+}$ chelating ability, and reducing power were lowest in germinated and non-germinated Superjami methanolic extracts among the rice samples analyzed (Table 3). The extracts from pigmented varieties showed significantly lower $\mathrm{EC}_{50}$ values on hydroxyl radical scavenging activity than that of brown rice. All rice samples exhibited a considerable decrease in $\mathrm{EC}_{50}$ values after germination.

Antioxidant components The anthocyanin was not detected in non-germinated brown rice and Superhongmi, but was present in germinated Superhongmi (Table 4). Furthermore, the total anthocyanin content in Superjami significantly increased after germination. Superhongmi showed considerably higher tannin content than Superjami. A marked increase in the tannin content was observed in both pigmented rice samples after germination. Tannin was not detected in the brown rice sample in both nongerminated and germinated forms. Germination significantly increased the total phenolic content in all rice samples. Superjami exhibited the highest total phenolic content, followed by Superhongmi, then the non-pigmented brown rice. Similarly, the phytic acid, tocopherol, and tocotrienol contents significantly increased after germination in all rice samples. Superjami and Superhongmi showed the highest amount of phytic acid in nongerminated and germinated forms, respectively. The tocopherol content was highest in Superjami and lowest in Superhongmi. The tocotrienol content, on the other hand, was highest in Superjami, followed by Superhongmi, then the non-pigmented brown rice.

\section{Discussion}

In the present study, the effect of germination for $72 \mathrm{~h}$ on the antioxidant capacity of blackish purple rice Superjami and reddish brown rice Superhongmi, in comparison to that of non-pigmented ordinary brown rice Hwacheong, was determined. Results showed that germination markedly increased the DPPH, ABTS, and hydroxyl radicals scavenging activities, $\mathrm{Fe}^{2+}$ chelating ability, reducing power, and SOD-like activity in all the rice samples. Moreover, the total anthocyanin, tannin, total phenolic, phytic acid, tocopherol, and tocotrienol contents were significantly higher in germinated rice compared to those of non-germinated ones. The $\mathrm{EC}_{50}$ values on DPPH and hydroxyl radical assays, $\mathrm{Fe}^{2+}$ chelating activity, and reducing power significantly decreased in all rice samples after germination. All rice samples, whether germinated or not, showed lower antioxidant capacity than the standard antioxidants BHA, EDTA, and ascorbic acid. Extracts from Superjami exhibited the lowest $\mathrm{EC}_{50}$ values and highest amount of antioxidant compounds, followed by that of Superhongmi, then brown rice. A past study on germinated rice also revealed that germination significantly enhanced the DPPH radical scavenging activity and reducing power in non-pigmented brown rice (Lin et al., 2015). Sutharut and Sudarat (2012) also observed an increase in the reducing power of pigmented rice after germination.

Since the antioxidant capacity of a food or plant extract differs depending on the type of oxidant involved in the analysis, it is essential to use a variety of assays to fully evaluate the antioxidant potential of the sample extract (MacDonald-Wicks et al., 2006). Antioxidants are classified into primary or chain-breaking antioxidants, which scavenge free radicals and convert them into 
Table 4. Antioxidant components in germinated and non-germinated pigmented rice.

\begin{tabular}{|c|c|c|c|}
\hline Antioxidant component & Rice sample & Non-germinated & Germinated \\
\hline \multirow{3}{*}{ Total anthocyanin content (mg malvidin/100 g extract) } & Brown rice & ND & ND \\
\hline & Superjami & $409.34 \pm 8.69$ & $729.22 \pm 9.11^{\mathrm{b}^{*}}$ \\
\hline & Superhongmi & ND & $18.36 \pm 2.85^{\mathrm{a}}$ \\
\hline \multirow{3}{*}{ Tannin content (mg TAE/g extract) } & Brown rice & ND & ND \\
\hline & Superjami & $152.14 \pm 9.61^{\mathrm{a}}$ & $1752.36 \pm 11.84^{\mathrm{a}^{*}}$ \\
\hline & Superhongmi & $1374.57 \pm 8.25^{\mathrm{b}}$ & $3654.54 \pm 10.21^{\mathrm{b}^{*}}$ \\
\hline \multirow{3}{*}{ Total phenolic content (mg GAE/100 g extract) } & Brown rice & $162.21 \pm 2.25^{\mathrm{a}}$ & $170.01 \pm 5.02^{\mathrm{a}}$ \\
\hline & Superjami & $242.11 \pm 4.72^{\mathrm{c}}$ & $476.42 \pm 2.98^{\mathrm{c}^{*}}$ \\
\hline & Superhongmi & $209.21 \pm 3.35^{\mathrm{b}}$ & $343.01 \pm 3.98^{\mathrm{b}^{*}}$ \\
\hline \multirow{3}{*}{ Phytic acid content (mg/100 g rice) } & Brown rice & $1.18 \pm 0.05^{\mathrm{a}}$ & $3.08 \pm 0.04^{\mathrm{a}^{*}}$ \\
\hline & Superjami & $2.45 \pm 0.16^{\mathrm{c}}$ & $5.40 \pm 0.03^{\mathrm{b}^{*}}$ \\
\hline & Superhongmi & $2.04 \pm 0.03^{\mathrm{b}}$ & $6.05 \pm 0.08^{\mathrm{c}^{*}}$ \\
\hline \multirow{3}{*}{ Tocopherol $(\alpha, \beta, \gamma)$ content $(\mu \mathrm{g} / 100 \mathrm{~g}$ rice $)$} & Brown rice & $25.01 \pm 2.40^{\mathrm{b}}$ & $77.64 \pm 2.08^{\mathrm{b}^{*}}$ \\
\hline & Superjami & $48.20 \pm 6.75^{\mathrm{c}}$ & $114.59 \pm 5.74^{\mathrm{c}^{*}}$ \\
\hline & Superhongmi & $5.19 \pm 6.05^{\mathrm{a}}$ & $17.25 \pm 0.32^{\mathrm{a}^{*}}$ \\
\hline \multirow{3}{*}{ Tocotrienol $(\alpha, \beta, \delta)$ content $(\mu \mathrm{g} / 100 \mathrm{~g}$ rice $)$} & Brown rice & $53.54 \pm 7.23^{\mathrm{a}}$ & $199.69 \pm 4.21^{\mathrm{a}^{*}}$ \\
\hline & Superjami & $156.44 \pm 8.10^{\mathrm{c}}$ & $305.37 \pm 6.50^{\mathrm{c}^{\mathrm{k}}}$ \\
\hline & Superhongmi & $126.84 \pm 6.40^{\mathrm{b}}$ & $267.26 \pm 5.38^{\mathrm{b}^{*}}$ \\
\hline
\end{tabular}

Values are means $\pm \mathrm{SD}(n=3)$. Means in the same column with different letters are significantly different at $P<0.05$. * indicates significant difference $(P<0.05)$ between germinated and non-germinated samples. ND, not detected.

stable molecules, and secondary or preventive antioxidants, which suppress radical formation and act as oxygen scavengers or chelators for catalyst metal ions (Wanasundra and Shahidi, 2005). The DPPH and ABTS radical scavenging assays measure the ability of the sample extract to donate an electron or hydrogen to stable free radicals DPPH and ABTS (Moon and Shibamoto, 2009). The hydroxyl scavenging assay determines the ability of the extract to scavenge hydroxyl radicals, the most reactive among the reactive oxygen species, generated via the Fenton reaction (Lee et al., 2004). The $\mathrm{Fe}^{2+}$ chelating ability assay, which measures the capacity of the compounds present in sample to compete with ferrozine for ferrous ion, is commonly used to assess the secondary antioxidant activity of the sample extract (Vladimir-Knezevic et al., 2011). The reducing power assay measures the capacity of the sample extract to donate electron to $\mathrm{Fe}^{3+} /$ ferricyanide complex, converting it to its ferrous form (Niki, 2010). The SOD-like activity assay measures the ability of the sample extract to catalyze the conversion of superoxide radicals into hydrogen peroxides, providing a defense mechanism against oxidative damage (Nagami et al., 2004). The relatively high free radical scavenging activities, $\mathrm{Fe}^{2+}$ chelating ability, reducing power, and SOD-like activity observed in Superjami and Superhongmi methanolic extracts, particularly those from germinated grains, suggest that these pigmented rice varieties have strong primary and secondary antioxidant potential.

The substantial increase in the antioxidant activities of germinated rice methanolic extracts may have been possibly due to the significant increase in the total phenolic, anthocyanin, tannin, phytic acid, tocopherol, and tocotrienol contents during germination of the grains. The anthocyanins, tannins, phenolics, phytic acid, tocopherols, and tocotrienols are natural antioxidant compounds that can scavenge free radicals and inhibit the formation of reactive oxygen species, thus preventing oxidative damage (Dai and Mumper, 2010; Goufo and Trindade, 2014; Ichikawa et al., 2001; Zhao et al., 2011). Several studies have shown that the antioxidant capacity of rice has a positive correlation with its phenolic content (Goffman and Bergman, 2004; Jin et al., 2009; Shen et al., 2009). Tian et al. (2004) previously reported that germination significantly increased the amount of phenolic acids in brown rice. Similarly, the total anthocyanin content has been found to increase in black rice after germination (Sutharut and Sudarat, 2012). Kaukorvirta-Norja et al. (2004) accounted that during germination, the cell walls surrounding various compounds are broken down and the free and bound phenolics are released leading to increased phenolic content in germinated rice. Furthermore, the dormant enzymes are activated to break down large molecular substances during germination, causing an increase in the nutrients and generation of bioactive components in rice (Moongngarm and Saetung, 2010). Pigmented rice are known to possess higher antioxidant capacity than ordinary non-pigmented varieties. Results of the present study demonstrate that germination for $72 \mathrm{~h}$ could further enhance the antioxidant 
activity and increase the amount of antioxidant compounds in pigmented rice.

\section{Conclusion}

Germination markedly increased the DPPH, ABTS, and hydroxyl radicals scavenging activities, ferrous ion chelating ability, reducing power, and SOD-like activity in both pigmented and non-pigmented rice samples. This increase in the antioxidant activity is possibly due to the substantial increase in the levels of anthocyanin, tannin, phenolic compounds, phytic acid, tocopherol, and tocotrienol in rice after germination. Extracts from pigmented rice, particularly Superjami, exhibited greater antioxidant activity and higher amounts of antioxidant components than that of the non-pigmented brown rice. The results illustrate that germination for $72 \mathrm{~h}$ can be a useful method in enhancing the antioxidant capacity of pigmented rice. Germinated Superjami and Superhongmi may be beneficial as functional foods with strong antioxidant potential.

Acknowledgement This research was supported by Basic Science Research Program through the National Research Foundation of Republic of Korea funded by the Ministry of Education (2014R1A1A2056797).

\section{Conflict of Interest}

The authors declare that they have no conflict of interest.

\section{References}

Chakuton, K., Puangpronpitag, D., and Nakornriab, M. (2012). Phytochemical content and antioxidant activity of colored and noncolored thai rice cultivars. Asian. J. Plant Sci., 11, 285-293.

Dai, J. and Mumper, R.J. (2010). Plant phenolics: extraction, analysis and their antioxidant and anticancer properties. Molecules, 15, 7313-7352.

Dutta, A.K., Gope, P.S., Banik, S. Makhnoon, S., Siddiquee, M.A., and Kabir, Y. (2012) Antioxidant properties of ten high yielding rice varieties of Bangladesh. Asian. Pac. J. Trop. Biomed., 2, S99-S103.

Goffman, F.D. and Bergman, C.J. (2004). Rice kernel phenolic content and its relationship with antiradical efficiency. J. Sci. Food Agric., 84, 12351240.

Goufo, P. and Trindale, H. (2014). Rice antioxidants: phenolic acids, flavonoids, anthocyanins, proanthocyanidins, tocopherols, tocotrienols, $\gamma$-oryzanol, and phytic acid. Food Sci. Nutr., 2, 75-104.

Hubner, F. and Arendt, E.K. (2013).Germination of cereal grains as a way to improve the nutritional value: a review. Crit. Rev. Food Sci. Nutr., 53, 853-861.

Ichikawa, H., Ichiyanagi, T., Xu, B., Yoshii, Y., Nakajima, M., and Konishi, T. (2001). Antioxidant activity of anthocyanin extract from purple black rice. J. Med. Food, 4, 211-218.

Islam, M.A. and Becerra. J.X. (2012). Analysis of chemical components involved in germination process of rice variety Jhapra. J. Sci. Res., 4, 251-262.
Jeng, T.L., Shih, Y.J., Ho, P.T., Lai, C.C., Lin, Y.W., Wang, C.S., and Sung, J.M. 2011. $\gamma$-Oryzanol, tocol and mineral compositions in different grain fractions of giant embryo rice mutants. J Sci. Food Agric., 92, 1468-1474.

Jiapong, S., Singanusong, R., and Jiamyangyuen, S. (2011). Effect of germination on antioxidative property of pigmented and non-pigmented rice. Thai J. Agric. Sci., 44, 277-282.

Jin, L., Xiao, P., Lu, Y., Shao, Y., Shen, Y., and Bao, J. (2009). Quantitative trait loci for brown rice color, phenolics, flavonoid contents, and antioxidant capacity in rice grain. Cereal Chem., 86, 609-615.

Kang, M.Y., Rico, C.W., Bae, H.J., and Lee, S.C. (2013). Antioxidant capacity of newly developed pigmented rice cultivars in Korea. Cereal Chem., 90, 497-501.

Kaukovirta-Norja, A., Wilhelmsson, A., and Poutanen, K. (2004) Germination: a means to improve the functionality of oat. Agric. Food. Sci., 13, 100-112.

Kwon, S.W., Chu, S.H., Han, S.J., and Ryu, S.N. (2011). A new rice variety 'Superjami' with high content of cyanidin 3-glucoside. Korean J. Breed. Sci., 43, 196-200.

Laokuldilok, T., Shoemaker, C.F., Jongkaewwattana, S., and Tulyathan, V. (2011). Antioxidants and antioxidant activity of several pigmented rice brans. J. Agric. Food Chem., 59, 193-199.

Lee, J., Koo, N., and Min, D.B. (2004). Reactive oxygen species, aging, and antioxidative nutraceuticals. Compr. Rev. Food Sci. Food Saf., 3, 21 33.

Lin, Y.T., Pao, C.C., Wu, S.T., and Chang, C.Y. (2015). Effect of different germination conditions on antioxidative properties and bioactive compounds of germinated brown rice. Biomed. Res. Int. doi $10.1155 / 2015 / 608761$.

Ling, W.H., Cheng, Q.X., Ma, J., and Wang, T. (2001). Red and black rice decrease artherosclerotic plaque formation and increase antioxidant status in rabbits. J. Nutr., 131, 1421-1426.

MacDonald-Wicks, L.K., Wood, L.G., and Garg, M.L. (2006). Methodology for the determination of biological antioxidant capacity in vitro: a review. J. Sci. Food Agric., 86, 2046-2056.

Marklund, S. and Marklund, G. (1974). Involvement of superoxide anion radical in autoxidation of pyrogallol and a convenient assay for superoxide dismutase. Eur. J. Biochem., 47, 469-474.

Mau, J.L., Huang, P.N., Huang, S.J., and Chen, C.C. (2003). Antioxidant properties of methanolic extracts from two kinds of Antrodia camphorata mycelia. Food Chem., 86, 25-31.

Mohd Esa, N., Abdul Kadir, K.K., Amom, Z., and Azlan, A. (2013). Antioxidant activity of white rice, brown rice and germinated brown rice (in vivo and in vitro) and the effects on lipid peroxidation and liver enzymes in hyperlipidaemic rabbits. Food Chem., 141, 1306-1312.

Moon, J.K. and Shibamoto, T. (2009). Antioxidant assays for plant and food components. J. Agric. Food Chem., 57, 1655-1666.

Moongngarm, A. and Khomphiphatkul, E. (2011). Germination time dependence of bioactive compounds and antioxidant activity in germinated rough rice (Oryza sativa L.). Am. J. Appl. Sci., 8, 15-25.

Moongngarm, A. and Saetung, N. (2010). Comparison of chemical 
compositions and bioactive compounds of germinated rough rice and brown rice. Food Chem., 122, 782-788.

Nagami, H., Umakoshi, H., Shimanouchi, T., and Kuboi, R. (2004). Variable SOD-like activity of liposome modified with Mn(II)-porphyrin derivative complex. Biochem. Eng. J., 21, 221-227.

Nam, S.H., Choi, S.P., Kang, M.Y., Kozukue, N., and Friedman, M. (2005). Antioxidative, antimutagenic, and anticarcinogenic activities of rice bran extracts in chemical and cell assays. J. Agric. Food Chem., 53, 816-822.

Niki, E. (2010). Assessment of antioxidant capacity in vitro and in vivo. Free Rad. Biol. Med., 49, 503-515.

Padma, R., Parvathy, N.G., Renjith, V., and Rahate, K.P. (2013). Quantitative estimation of tannins, phenols, and antioxidant activity of methanolic extract of Imperata cylindrica. Int. Res. Pharm. Sci., 4, 7377.

Patil, S.B. and Khan, M.K. (2011). Germinated brown rice as a value added rice product: a review. J. Food Sci. Technol., 48, 661-667.

Privita-Edwina, R.G.E., Ajitha, C., Eganathan, P., Gayathri, S., Saranya, J., Arivudai Nambi, V., Smita, M., and Susanta Sekhar, C. (2014). Biochemical and antioxidant activities of pigmented landraces of Oryza sativa - Koraput District, Odisha, India. Int. Food Res. J., 21, 1941 1949.

Seo, W.D., Kim, J.Y., Han, S.I., Ra, J.E., Lee, J.H., Song, Y.C., Park, M.J., Kang, H.W., Oh, S.K., and Jang, K.C. (2011). Relationship of radical scavenging activities and anthocyanin contents in the 12 colored rice varieties in Korea. J. Korean Soc. Appl. Biol. Chem., 54, 693-699.

Shen, Y., Jin, L., Xiao, P., Lu, Y., and Bao, J. (2009). Total phenolics, flavonoids, antioxidant capacity in rice grain and their relations to grain color, size and weight. J. Cereal Sci., 49, 106-111.

Sudan, R., Bhagat, M., Gupta, S., Singh, J., and Koul, A. (2014). Iron (FeII) chelation, ferric reducing antioxidant power, and immune modulating potential of Arisaema jacquemontii (Himalayan Cobra Lily). Biomed.
Res. Int. doi: 10.1155/2014/179865.

Sutharut, J. and Sudarat, J. (2012). Total anthocyanin content and antioxidant activity of germinated colored rice. Int. Food Res. J., 19, 215-221.

Tian, S., Nakamura, K., and Kayahara, H. (2004). Analysis of phenolic compounds in white rice, brown rice, and germinated brown rice. $J$. Agric. Food Chem., 52, 4808-4813.

Umnajkitikorn, K., Faiyue, B., and Saengnil, K. (2013). Enhancing antioxidant properties of germinated Thai rice (Oryza sativa L.) cv. Kum Doi Saket with salinity. J. Rice Res., 1, 103.

Velioglu, Y.S., Mazza, G., Gao, L., and Oomah, B.D. (1998). Antioxidant activity and total phenolics in selected fruits, vegetables, and grain products. J. Agric. Food Chem., 46, 4113-4117.

Vladimir-Knezevic, S., Blazekovic, B., Stefan, M.B., Alegro, A., Koszegi, T., and Petrik, J. (2011). Antioxidant activity and polyphenolic contents of three selected Micromeria species from Croatia. Molecules, 16, 14541470.

Wanasundara, P.K.J.P.D. and Shahidi, F. (2005). Antioxidants: science, technology, and applications. Pages 431-489 in: Bailey’s Industrial Oil and Fat Products, Vol. 1, 6th edition. F. Shahidi, ed. John Wiley and Sons, Inc.: New Jersey.

Wu, F., Chen. H., Yang, N., Wang, J., Duan, X., Jin, Z., and Xu, X. (2013a). Effect on germination time on physicochemical properties of brown rice flour and starch from different rice cultivars. J. Cereal Sci., 58, 263-271.

Wu, F., Yang, N., Toure, A., Jin, Z., and Xu, X. (2013b). Germinated brown rice and its role in human health. Crit. Rev. Food Sci. Nutr., 53, 451-463.

Zhao, S., Liu, J.Y., Chen, S.Y., Shi, L.L., Liu, Y.J., and Ma, C. (2011). Antioxidant potential of polyphenols and tannins from burs of Catanea mollissima blume. Molecules, 16, 8590-8600. 